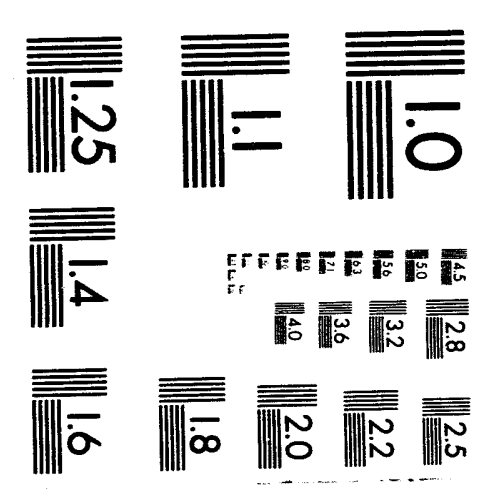



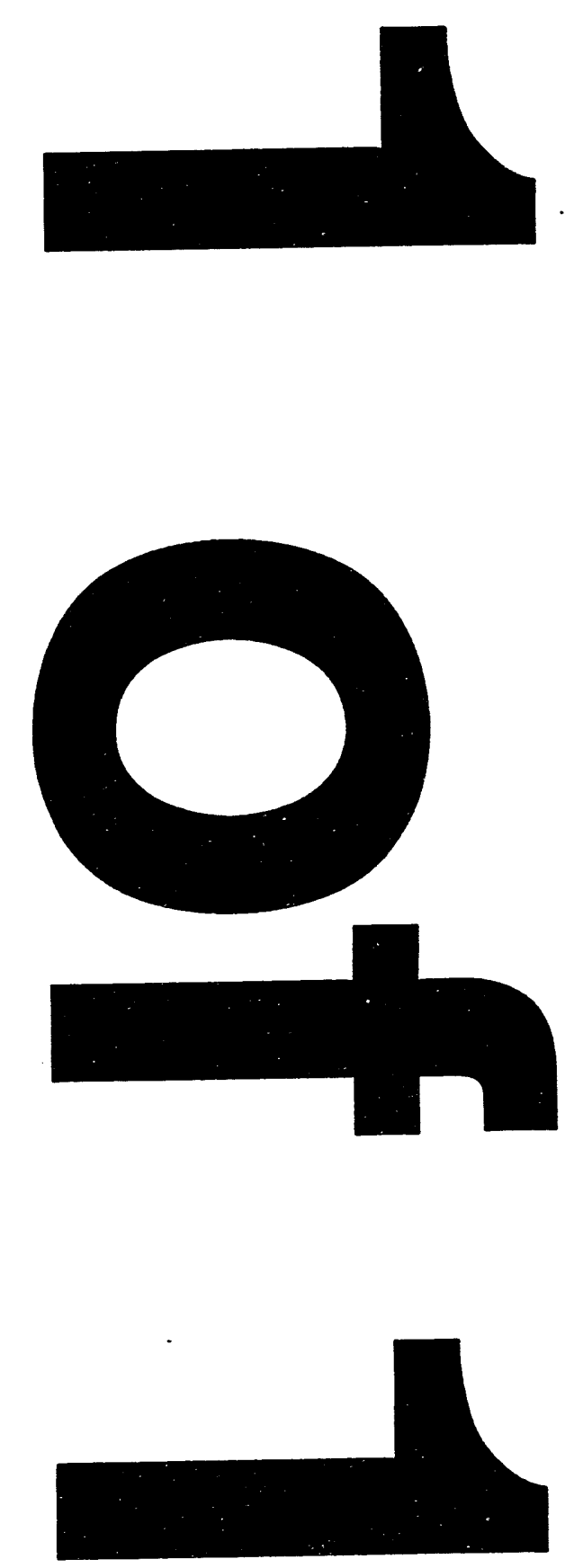


\section{STRUCTURES OF TWO PRECURSORS TO ORGANIC CHARGE-TRANSFER \\ SALTS: 1,3-dithiolo[4,5-b][1,4]dithlin-2-thione and 1,3-dithiolo[4.5-b] \\ $[1,4]$ dithilin-2-one}

M. A. Beno, A. M. Kini, and J. M. Williams

Argonne National Laboratory

Materials Science Division

Argonne, IL 60439

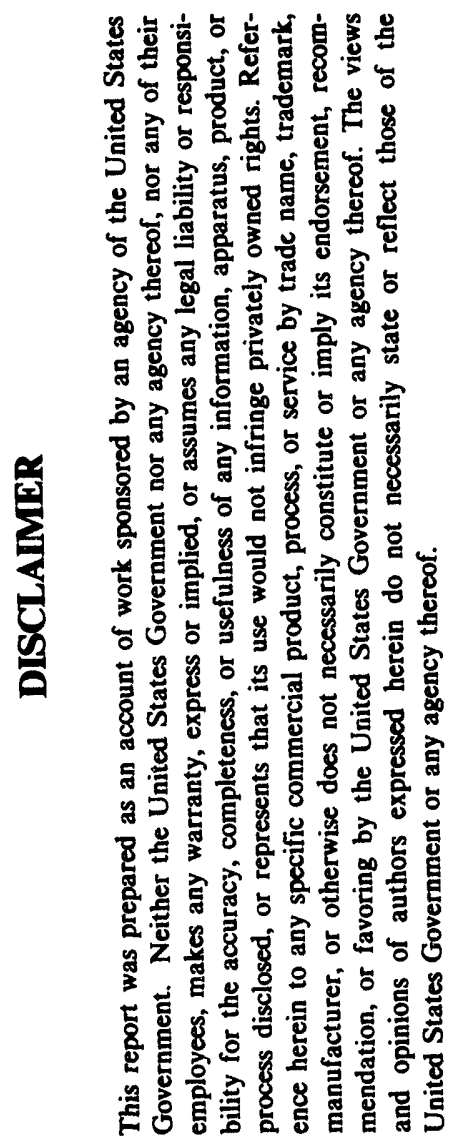

September 1990

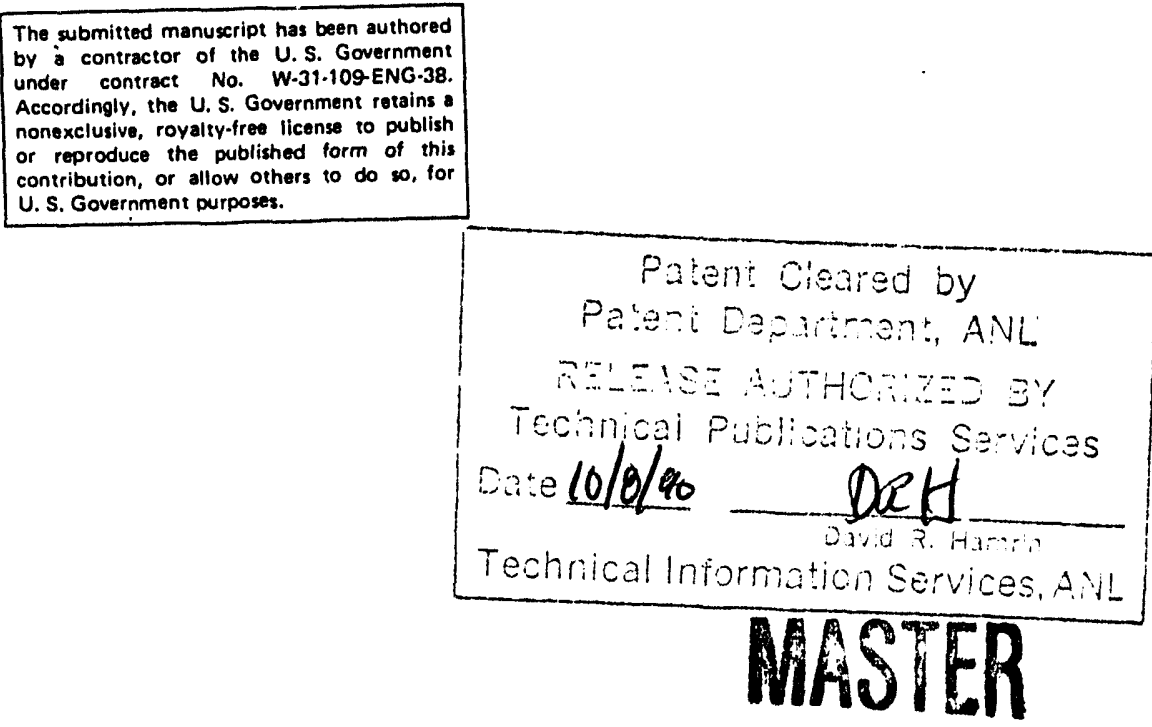

*Work Supported by the U.S. Department of Energy, BES-Materials Sciences, under Contract W-31-109-ENG-38. 
Structures of Two Precursors to Organic Charge-Transfer Salts: 1,3-dithiolo[4,5-b][1,4]dithiln-2-thione and 1,3-dithiolo[4,5-b] [1,4]dithiln2-one

By M. A. Beno", A. M. Kini and J. M. Williams

Materials Science and Chemistry Divisions, Argonne National Laboratory, Argonne, Illinios 60439, USA

Author to whom correspondence should be addressed. 
Abstract. $\mathrm{C}_{5} \mathrm{H}_{4} \mathrm{~S}_{4} \mathrm{O}(1), \mathrm{Mr}_{\mathrm{r}}=208.343$, monoclinic, $\mathrm{P} 2{ }_{1} / \mathrm{n}, a=5.664(2), b=16.535$ (6), $c=7.281$ (2) $\AA, \beta=97.84$ (3), $V=794.8$ (5) $\AA^{3}, Z=4, D_{x}=1.741 \mathrm{Mg} \mathrm{m}^{-3}, \lambda$ (Mo $K \alpha)=0.71073 \AA, \mu=1.0 \% \mathrm{~mm}^{-1}, F(000)=424, T=298 \mathrm{~K}, R(F)=0.048$ for 2338 reflections. $\mathrm{C}_{5} \mathrm{H}_{4} \mathrm{~S}_{5}(2), \mathrm{M}_{r}=224.39$, monoclinic, $\mathrm{P} 2{ }_{1} / \mathrm{n}, a=10.765$ (2), $b=5.879$ (2),

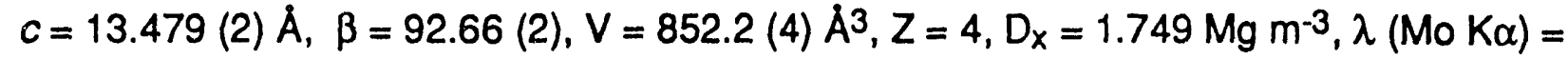
$0.71073 \AA, \mu=1.23 \mathrm{~mm}^{-1}, F(000)=456, T=298 \mathrm{~K}, R(F)=0.059$ for 2491 reflections. Structure determinations for the intermediates 1 and 2 were undertaken as part of a qualitative theoretical study of the changes in the geometries of organic donor molecules which occur with charge transfer. Although the geometries of 1 and 2 are nearly identical, the packing of these molecules in the unit cells is quite different. The molecular packing patterns are undoubtedly related to differences in the $\mathrm{C}-\mathrm{H} \cdots$ chalcogen interactions for the thio and keto substituents.

Introduction. The charge-transfer salts based on (BEDT-TTF) bis-(ethylenedithio)tetrathiafulvalene which include metals, semiconductors and superconductors (Williams, Wang, Emge, Geiser, Beno, Leung, Carlson, Thorn, Schultz \& Whangbo, 1987), consist of stacks of relatively planar organic donor molecules which are linked by short (less than the van der Waals radii sum, 3.6 $\AA$, Bondi, 1964) inter- and intrastack S...S interactions. A large number of stacking patterns have been observed and are dependent on the size and symmeiry of the counter-anions (Emge, Leung, Beno, Wang, Firestone, Webb, Carlson, Williams, Venturini, Azevedo \& Schirber,1986; Wang, Allen, Schlueter, Hallenbeck, Stupka, Chen, Despotes, Kao, Carlson, Geiser \& Williams, 1987) as well as donor...donor and donor...anion hydrogen bonding interactions (Leung, Emge, Beno, Wang, Williams, Petricek \& Coppens, 1985; Whangbo, Williams, Schultz, Emge \& Beno, 1987; Whangbo, Williams, Schultz \& Beno, 1987). In contrast to the BEDT-TTF salts, only one donor packing pattern is observed in the (BEDO-TTF) bis-(ethylenedioxo)tetrathiafulvalene salts (Beno, Wang, Carlson, Kini, Frankenback, Ferraro, Larson, McCabe, Thompson, Purnama, Vashon, Williams, Jung \& Whangbo, 1990). The crystal and molecular structures of the intermediates 1 and 2 (see Fig. 1) were determined as part of a qualitative theoretical study of the intermolecular interactions that control donor stacking and are important in determining the molecular geometries of the BEDT-TTF and BEDO-TTF donor molecules (Whangbo, Jung, Ren, Evain, Novoa, Mota, Alvarez, Williams, Beno, Kini, Wang \& Ferraro, 1990).

Figure 1 Here 
Experimental. The molecules 1 and 2 were synthesized as reported by Kini (Kini, Beno \& Williams, 1987) and recrystallized in THF (tetra-hydrofuran). For 1, transparent plates, $0.55 \times 0.33 \times 0.075 \mathrm{~mm}$. For 2, transparent needles, $0.38 \times 0.14 \times$ $0.07 \mathrm{~mm}$. Nicolet $\mathrm{P} 2{ }_{1}$ automated diffractometer. Unit cell dimensions from leastsquares based on the setting-angles of 25 reflections $\left(12^{\circ}<2 \theta<20^{\circ}\right)$. Intensity data were collected using the $\omega$ scan technique with monochromatized Mo $\mathrm{K} \alpha$ radiation and variable scan speeds of 2 to $12^{\circ} \mathrm{min}^{-1}$ to $\sin \theta \lambda=0.70,0 \leq h \leq 9,0 \leq k \leq 23,-10 \leq 1$ $\leq 10$ for 1 and $0 \leq h \leq 15,0 \leq k \leq 8,-18 \leq 1 \leq 18$ for 2 . Three standard reflections measured every 100 reflections showed $<3 \%$ intensity variation. Data were corrected for Lorentz and polarization effects, a Gaussian absorption correction $(8 \times 8 \times 8)$ procedure was used and multiply measured reflections (standards and $0 \mathrm{kl}$ zone) were averaged. For $1, T_{\min }=0.71, T_{\max }=0.92$ with $R_{\text {int }}\left(F_{0}\right)=0.021$ for 2338 reflections. In the case of $2, T_{\min }=0.83, T_{\max }=0.93$ with $R_{\text {int }}\left(F_{0}\right)=0.027$ for 2491 reflections. In each case the space group was indicated by systematic absences to be $P 21 / n$. The structures were solved using MULTAN78 (Main, Hull, Lessinger, Germain, Declercq \& Woolfson, 1978) and Fourier methods. Hydrogen atoms, which could be observed in Fourier maps were included at calculated positions with $B_{i s o}=5.0 \AA^{2}$. All nonhydrogen atoms were refined with anisotropic temperature factors. A secondary extinction correction was tested for both structures and found to be significant for 1 with a value of $0.81(13) \cdot 10^{-5}$. The function minimized was $\Sigma w\left(\left|F_{\mathrm{o}}\right|-\left|F_{\mathrm{c}}\right|\right)^{2}$ where $W=1 / \sigma^{2}\left(F_{0}\right)$ and $\sigma\left(F_{0}\right)=\left[\sigma^{2}\left(F_{0}^{2}\right)+\left(0.02 F_{0}^{2}\right)^{2}\right]^{1 / 2} / 2 F_{0}$, with the value of $\sigma\left(F_{0}^{2}\right)$ based on counting statistics. $\Delta \sigma \sigma \leq 0.05$ in the final least-squares cycle resulted in $R\left(F_{0}\right)=0.048$, $w R\left(F_{0}\right)=0.041$ and $S=1.94$ for 92 variable parameters and 2158 data with $F_{0} \geq 0.0$ in the case of 1 and $R\left(F_{0}\right)=0.060, w R\left(F_{0}\right)=0.042$ and $S=1.77$ for 91 refined parameters and 2302 observed data $\left(F_{0}>0.0\right)$ in the case of 2 . Atomic scattering factors including anomalous contributions were taken from the International Tables for $X$-ray Crystallography (1974). Calculations were done using a local modification of the UCLA Crystallographic Package (Strouse, 1978).

Discussion. The atomic numbering scheme and conformation of the molecules are shown in Fig. 1. With the exception of the ethylene carbon atoms, the molecules are planar. In the case of 1 , the ethylene carbon atoms are displaced on opposite sides of the molecular plane, $\mathrm{C} 4$ on one side by $-0.22 \AA$ and $\mathrm{C} 5$, on the opposite side, by 0.51 $\AA$. The same conformation for the five- and six-membered rings is observed in the crystal structure of 5,6-dihydro-5,6-dimethyl-1,3-dithiolo [4,5-b] [1,4]dithiin-2-thione (3) (Wallis \& Dunitz, 1988), a chiral molecule similar to 2, but with methyl groups unsymmetrically substituted at carbon atoms $\mathrm{C} 4$ and $\mathrm{C} 5$. In contrast, both carbon 
atoms in 2 are on the same side of the molecular plane, $C 4$ by $0.03 \AA$ and $C 5$ by 0.81 $\AA$. In BEDT-TTF salts both conformations for the six-membered rings are observed (Williams et al, 1987). Theoretical calculations show that the different conformations are very close in energy and that the observed conformation is dictated by molecular packing considerations (Jung, Evain, Novoa, Whangbo, Beno, Kini, Schultz, Williams \& Nigrey, 1989; Whangbo, Jung, Ren, Evain, Novoa, Mota, Alvarez, Williams, Beno, Kini, Wang \& Ferraro, 1990). The final positional and equivalent isotropic thermal parameters are given in Table $1^{*}$. Bond distances and angles appear in Table 2. The bond lengths and angles in $\mathbf{2}$ are nearly identical to those found in $\mathbf{3}$ and are similar to those observed in 1 and in the neutral BEDT-TTF molecule (Kobayashi, Kobayashi, Sasaki, Saito \& Inokuchi, 1986).

\section{Figure 2 Here}

The molecular packing observed in 2, as depicted in Figure 2, is dominated by the occurrence of centrosymmetrically related pairs of molecules. This packing is similar to that which occurs in the non-centrosymmetric structure 3. The short intermclecular interactions which occur in both molecules are given in Table 3. As is shown in Figure 3 , the keto oxygen of 1 is surrounded by 4 nearest neighbor hydrogen atoms at a distance of less than $2.95 \AA$ (the van der Waals radii sum for $\mathrm{H}$ and $\mathrm{O}$ atoms, Bondi, 1964). As in the case of 1 , the occurrence of short $\mathrm{C}-\mathrm{H}$... O interactions is a controlling factor in the molecular packing observed in neutral BEDO-TTF (Whangbo et al, 1990), and is important in BEDO-TTF salts (Beno et al, 1990).

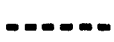

Figure 3 Here

Work at Argonne National laboratory is sponsored by the US Department of Energy, Office of Basic Energy Sciences, Division of Materials Sciences, under contract W-31109-ENG-38.

\footnotetext{
- Lists of structure factors, anisotropic thermal parameters, and calculated hydrogen atom positions have been deposited with the British Library Document Supply Centre as Supplementary Publication No. xxxxx (xx pp.). Copies may be obtained through the Executive Secretary, International Union of Crystallography, 5 Abbey Square, Chester $\mathrm{CH} 12 \mathrm{HU}$, England.
} 


\section{References}

Beno, M. A., Wang, H. H., Carlson, D. K., Kini, A. M., Frankenback, G. M., Ferraro, J. R., Larson, N., McCabe, G. D., Thompson, J., Purnama, C., Vashon, M., Williams,J. M., Jung D. \& Whangbo, M.-H. (1990) Mol. Cryst. Liq. Cryst. 181, 145-159.

Bondi, A. (1964). J. Phys. Chem. 68, 441-451.

Emge, T. J., Leung, P. C. W., Beno, M. A., Wang, H. H., Firestone, M. A., Webb, K. S., Carlson, K. D., Williams, J. M., Venturini, E. L., Azevedo, L. J. \& Schirber, J. E. (1986). Mol. Cryst. Liq. Cryst. 132, 363-383.

Kini, A. M., Beno, M. A. \& Williams, J. M. (1987). Chem Commun. pp. 335-336. Leung, P. C. W., Emge, T. J., Beno, M. A., Wang, H. H., Williams, J. M., Petricek, V. \& Coppens, P. (1985). J. Am. Chem. Soc. 107, 6184-6191.

International Tables for X-ray Crystallography (1974). Vol. IV. Birmingham: Kynoch Press. (Present distributor D. Reidel, Dordrecht. )

Jung, D., Evain, M., Novoa, J. J., Whangbo, M.-H., Beno, M. A., Kini, A. M., Schultz, A. J., Williams, J. M. \& Nigrey P. J. (1989). Inorg. Chem. 28, 4516-4522.

Kobayashi, H., Kobayashi, A., Sasaki, Y., Saito, G. \& Inokuchi, H. (1986). Bull. Chem. Soc. Jpn. 59, 301-302.

Main, P., Hull, S. E., Lessinger, L., Germain, G., Declercq, J.-P. \& Woolfson, M. M. (1978), MULTAN78. A System of Computer Programs for the Automatic Solution of Crystal Structures from X-ray Diffraction Data. Univs. of York, England, and Louvain, Belgium.

Strouse, C. (1978). UCLA Crystallographic Package. Univ. of California, Los Angeles. Wallis, J. D. \& Dunitz, J. D. (1988). Acta. Cryst. C44, 1037-1039.

Wang, H. H., Allen, T. J., Schlueter, J. A., Hallenbech, S. L., Stupka, D. L., Chen, M. Y., Despotes, A. M., Kao, H.-C. I., Carlson, K. D., Geiser, U. \& Williams, J. M. (1987).

Proceedings: The Vth International Conference on the Chemistry of Selenium and Tellurium, August 24-28, 1987, Oak Ridge, Tennessee, to be published in Phosphorus and Sulfur.

Whangbo, M.-H., Jung, D., Ren, J., Evain, M., Novoa, J. J., Mota, F., Alvarez, S., Williams, J. M., Beno, M. A., Kini, A. M., Wang, H. H. \& Ferraro, J. R. (1990). in Proceedings of The First ISSP International Symposium on the Physics and Chemistry of Organic Superconductors, Berlin, Springer-Verlag, in press.

Whangbo, M. H., Williams, J. M., Schultz, A. J., Emge, T. J. \& Beno, M. A. (1987). J. Am. Chem. Soc. 109, 90-94.

Whangbo, M. H., Williams, J. M., Schultz, A. J. \& Beno, M. A. (1987). Organic and Inorganic Low-Dimensional Crystalline Materials, pp. 333-336, New York: Plenum Press. 
Williams, J. M., Wang, H. H., Emge, T. J., Geiser, U., Beno, M. A., Leung, P. C. W., Carlson, K. D., Thorn, R. J., Schultz, A. J. \& Whangbo, M. H. (1987). Progress in Inorganic Chemistry, Vol. 35. New York: John Wiley \& Sons, pp. 51-218. 


\section{Figure Captions}

Fig. 1. Atom numbering scheme and configuration of 1, 1,3-dithiolo[4,5-b] [1,4]dithiin2-one, and 21,3-dithiolo[4,5-b][1,4]dithiin-2-thione The thermal ellipsoids are drawn at the $50 \%$ probability level with hydrogen atoms reduced to $B_{\text {iso }}=1.0 \AA^{2}$ for clarity.

Fig. 2. Stereoscopic views of the molecular packing in 1 (top) and 2 (bottom). The short $\mathrm{C}-\mathrm{H}$... O interactions which occur in 1 result in pancake like stacks in which the direction of the molecules alternates along the stacks. In contrast, the absence of these interactions in 2 produces dimerized stacks of molecules, a packing mode similar to the $\mathrm{k}$-phase BEDT-TTF salts.

Fig. 3. Intermolecular $\mathrm{O} \cdots \mathrm{H}$ contacts less than $2.95 \AA$ in 1 indicated by the thin lines, serve both to connect molecules in the stack (right hand side of the figure) and to link adjecent stacks (left hand side of the figure).. The thermal ellipsoids are drawn at the $20 \%$ probability level. 
Figure 1
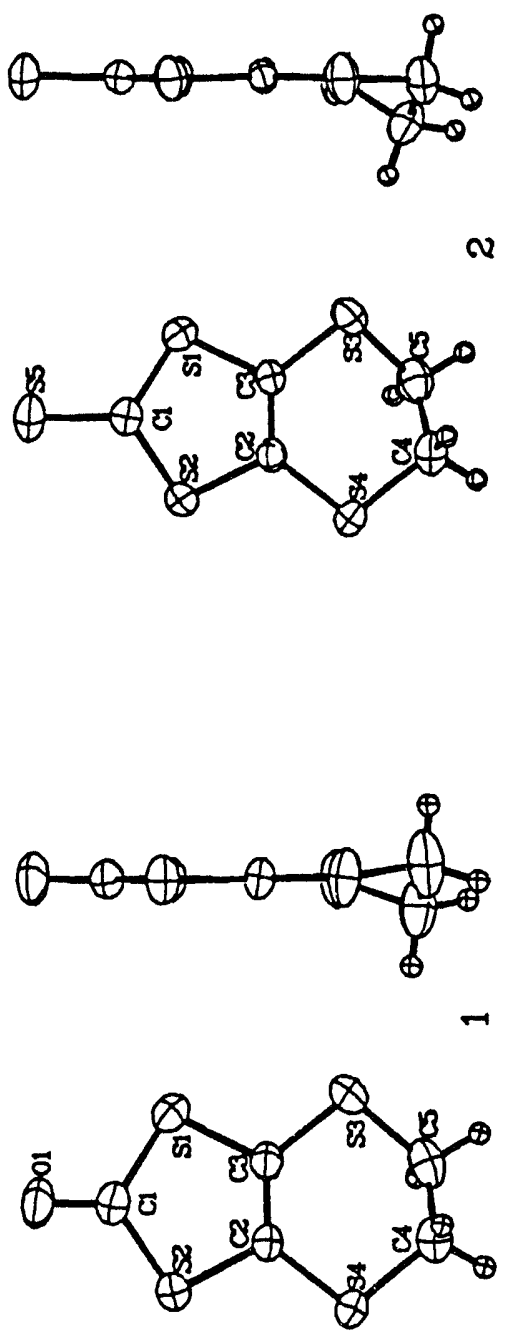

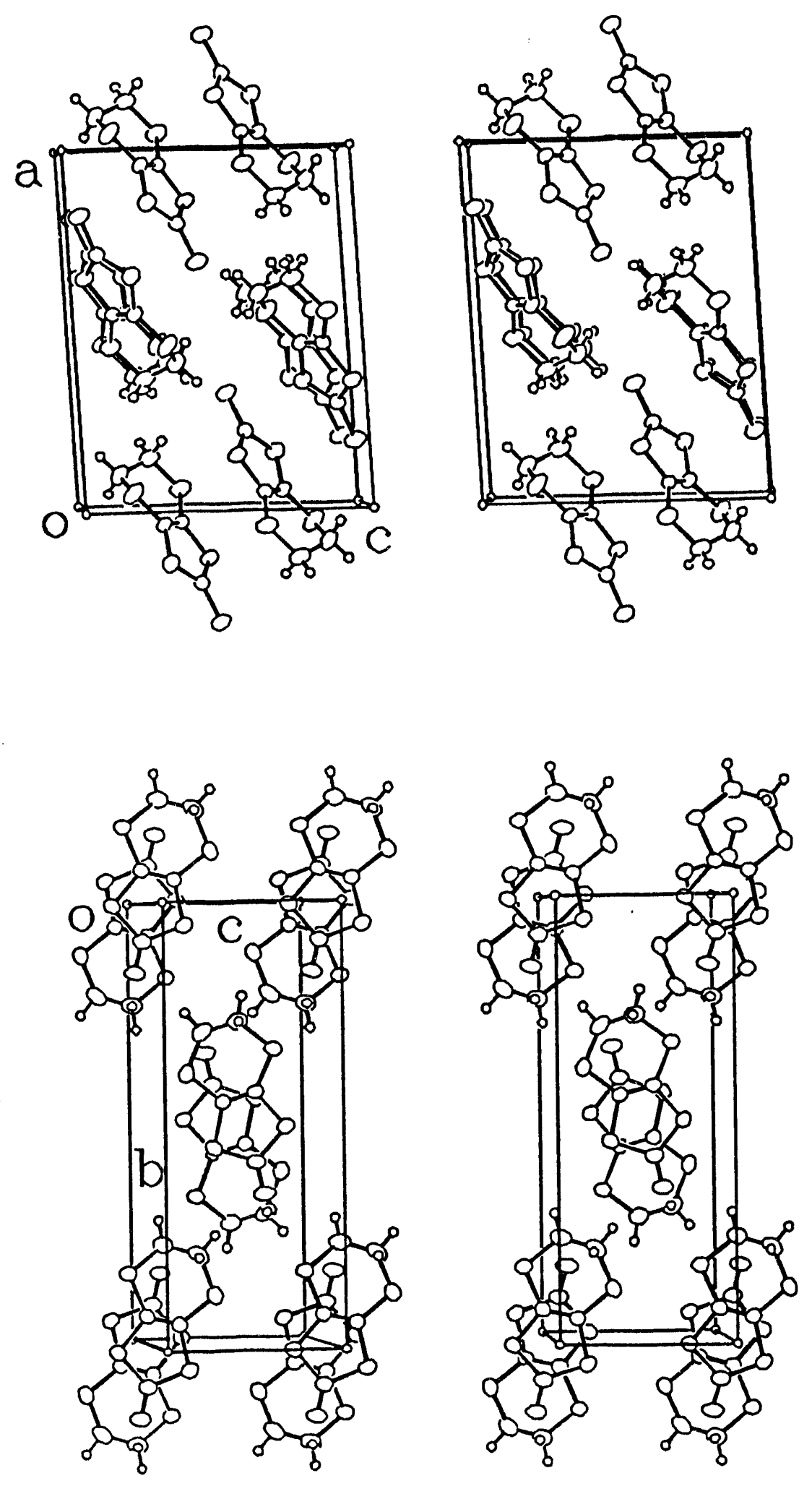

Figure 2 

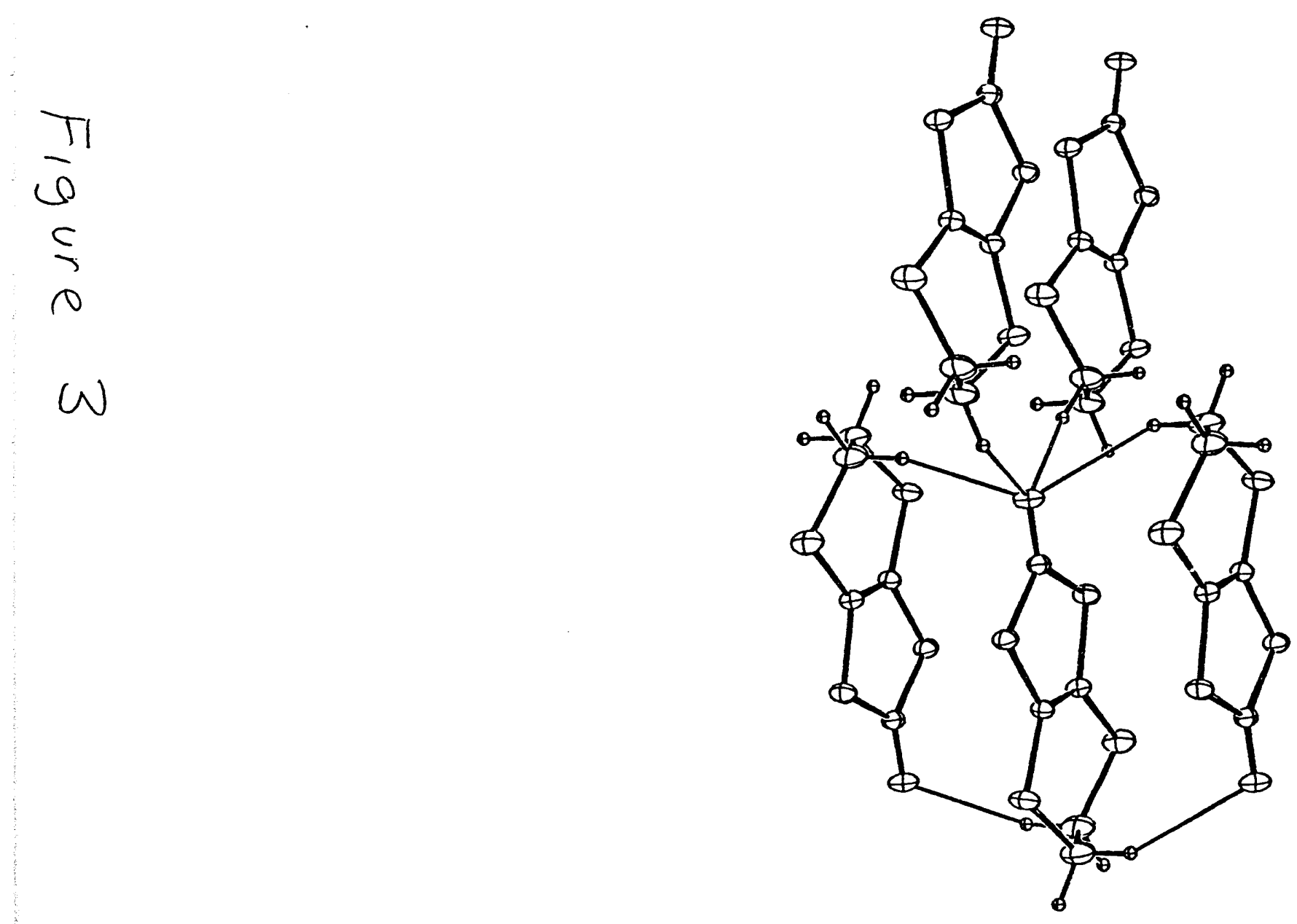
Table 1 Positional and Equivalent Isotropic Thermal Parameters

$\begin{array}{lcclc}\text { Atom } & x & \mathrm{C}_{5} \mathrm{H}_{4} \mathrm{~S}_{5} & \\ \text { S1 } & 0.94471(7) & 0.18042(12) & 0.35378(5) & 416(2) \\ \text { S2 } & 0.79454(7) & -0.22122(12) & 0.35127(5) & 447(2) \\ \text { S3 } & 0.86517(8) & 0.35619(13) & 0.54608(5) & 493(2) \\ \text { S4 } & 0.68131(8) & -0.13391(14) & 0.54474(6) & 586(3) \\ \text { S5 } & 0.95871(8) & -0.13776(15) & 0.18395(5) & 549(3) \\ \text { C1 } & 0.9025(2) & -0.0651(4) & 0.2915(2) & 355(7) \\ \text { C2 } & 0.7853(2) & -0.0493(4) & 0.4559(2) & 361(8) \\ \text { C3 } & 0.8553(2) & 0.1406(4) & 0.4569(2) & 318(7) \\ \text { C4 } & 0.6445(3) & 0.1417(6) & 0.5934(2) & 548(10) \\ \text { C5 } & 0.7569(3) & 0.2648(6) & 0.6365(2) & 539(10) \\ & & & & \\ & & & & \\ \text { Atom } & x & y 5 H_{4} 0 S_{4} & & U_{\text {eq }}{ }^{*} 104 a \\ \text { S1 } & 0.18216(8) & 0.05148(3) & 0.28596(9) & 474(2) \\ \text { S2 } & -0.24508(8) & 0.00603(3) & 0.20600(8) & 444(2) \\ \text { S3 } & 0.33691(8) & -0.11518(4) & 0.31790(11) & 626(3) \\ \text { S4 } & -0.17594(8) & -0.16967(3) & 0.22588(10) & 537(2) \\ \text { C1 } & -0.0701(3) & 0.08545(12) & 0.2402(3) & 417(7) \\ \text { C2 } & -0.0696(3) & -0.07267(11) & 0.2419(3) & 371(6) \\ \text { C3 } & 0.1257(3) & -0.05184(12) & 0.2776(3) & 396(6) \\ \text { C4 } & 0.0395(4) & -0.2319(2) & 0.2966(5) & 724(11) \\ \text { C5 } & 0.2292(4) & -0.2085(2) & 0.2309(4) & 703(11) \\ \text { O1 } & -0.1164(3) & 0.15637(9) & 0.2323(2) & 592(6)\end{array}$

a The complete temperature factor is $\exp \left(-8 \pi^{2} U_{e q} \sin ^{2} \theta / \lambda^{2}\right)$, where $U_{e q}=1 / 3 \sum_{i j} U_{i j} a^{*} ; a^{*} j a_{i} a_{j}$ in units of $\AA^{2}$. 
Table 2. Interatomic Distances and Angles.

\begin{tabular}{|c|c|c|c|c|c|c|c|}
\hline \multicolumn{8}{|c|}{$\mathrm{C}_{5} \mathrm{H}_{4} \mathrm{~S}_{4} \mathrm{O}$} \\
\hline Atoms & Dist. (A) & Atoms & Dist. & $(A)$ & toms & Dist & $(\AA)$ \\
\hline$S 1-C_{1}$ & $1.760(2)$ & S2-C1 & 1.75 & $52(2)$ & $1-C 3$ & 1.7 & $49(2)$ \\
\hline $\mathrm{S} 2-\mathrm{C} 2$ & $1.745(2)$ & S3-C3 & 1.7 & $47(2)$ & $3-C 5$ & 1.7 & $82(3)$ \\
\hline$S 4-C 2$ & $1.751(2)$ & S4-C4 & 1.78 & $85(3)$ & $1-01$ & 1.2 & 12(2) \\
\hline $\mathrm{C} 2-\mathrm{C}_{3}$ & $1.337(3)$ & C4-C5 & 1.46 & $64(4)$ & & & \\
\hline Atoms & Angle $\left({ }^{\circ}\right)$ & Atoms & & Angle $\left({ }^{\circ}\right)$ & Atom & & Angle $\left(^{\circ}\right)$ \\
\hline C3-S1-C1 & $196.30(10)$ & C2-S2-C & & $96.79(10)$ & C3-S & $3-C 5$ & $100.56(11)$ \\
\hline $\mathrm{C} 2-\mathrm{S} 4-\mathrm{C} 4$ & $4101.95(11)$ & O1-C1-s & & $123.9(2)$ & $01-\mathrm{C}$ & $1-S 1$ & $123.2(2)$ \\
\hline$S 2-C_{1-S 1}$ & $1112.82(12)$ & C3-C2-S & & $116.8(2)$ & C3-C & $2-54$ & $128.6(2)$ \\
\hline S2-C2-S4 & $4114.60(11)$ & C2-C3-S & & 128.2(2) & $\mathrm{C} 2-\mathrm{C}$ & $3-51$ & $117.2(2)$ \\
\hline S3-C3-S1 & $1114.53(12)$ & C5-C4-S & $\$ 4$ & $116.7(2)$ & C4-C & $5-53$ & $115.9(2)$ \\
\hline
\end{tabular}

$\begin{array}{llllll}\text { Atoms } & \text { Dist. }(\AA) & \text { Atoms } & \begin{array}{c}\mathrm{C}_{5} \mathrm{H}_{4} \mathrm{~S}_{5} \\ \text { Dist. }(\AA)\end{array} & \text { Atoms } & \text { Dist. }(\AA) \\ \mathrm{S} 1-\mathrm{C} 1 & 1.721(3) & \mathrm{S} 1-\mathrm{C} 3 & 1.742(2) & \mathrm{S} 2-\mathrm{C} 1 & 1.712(3) \\ \mathrm{S} 2-\mathrm{C} 2 & 1.743(3) & \mathrm{S} 3-\mathrm{C} 3 & 1.747(2) & \mathrm{S} 3-\mathrm{C} 5 & 1.807(3) \\ \mathrm{S} 4-\mathrm{C} 2 & 1.749(2) & \mathrm{S} 4-\mathrm{C} 4 & 1.800(3) & \mathrm{S} 5-\mathrm{C} 1 & 1.653(3) \\ \mathrm{C} 2-\mathrm{C} 3 & 1.346(3) & \mathrm{C} 4-\mathrm{C} 5 & 1.503(4) & & \end{array}$

$\begin{array}{llllll}\text { Atoms } & \text { Angle }\left({ }^{\circ}\right) & \text { Atoms } & \text { Angle }\left({ }^{\circ}\right) & \text { Atoms } & \text { Angle }\left(^{\circ}\right) \\ \text { C1-S1-C3 } & 97.68(12) & \text { C1-S2-C2 } & 97.79(12) & \text { C3-S3-C5 103.19(13) } \\ \text { C2-S4-C4 } & 98.76(13) & \text { S5-C1-S2 } & 123.9(2) & \text { S5-C1-S1 123.1(2) } \\ \text { S2-C1-S1 } & 112.94(14) & \text { C3-C2-S2 } & 115.8(2) & \text { C3-C2-S4 } 127.2(2) \\ \text { S2-C2-S4 } & 116.84(15) & \text { C2-C3-S1 } & 115.7(2) & \text { C2-C3-S3 } 128.6(2) \\ \text { S1-C3-S3 } & 115.68(14) & \text { C5-C4-S4 } & 112.8(2) & \text { C4-C5-S3 114.5(2) }\end{array}$


Table 3. Intermolecular Contact Distances.

\section{$\mathrm{C}_{5} \mathrm{H}_{4} \mathrm{~S}_{4} \mathrm{O}$}

Atom1 Atom2

S3 S4

H4A O1

H4B 01

H5A O1

H5B 01

Dist (A)

3.5205(13)

$2.773(2)$

$2.706(2)$

$2.431(2)$

2.489(2)

Symmetry Operation (Atom2)

$x+1, \quad y, \quad z$

$-x-1 / 2, \quad y-1 / 2, \quad-z+1 / 2$

$-x, \quad-y, \quad-z+1$

$\begin{array}{lll}-x+1 / 2, & y-1 / 2, & -z+1 / 2 \\ -x, & -y, & -z\end{array}$

\section{$\mathrm{C}_{5} \mathrm{H}_{4} \mathrm{~S}_{5}$}

Atom1 Atom2

S3 S5

S3 S4

$\mathrm{H} 4 \mathrm{~A}$ S5

H4B S5

H5B S5

Dist (A)

3.3882(12)

$3.5916(12)$

3.190(2)

$3.134(2)$

3.053(2)
Symmetry Operation (Atom2)

$x-1 / 2, \quad-y-1 / 2, \quad z+1 / 2$

$x, \quad y-1, \quad z$

$x-1 / 2, \quad-y-1 / 2, \quad z+1 / 2$

$-x+1.5, \quad y+1 / 2, \quad-z+1 / 2$

$-x+2, \quad-y, \quad-z+1$ 
Supplementary information for:

Structures of Two Precursors to Organic Charge-Transfer Salts: 1,3-dithiolo[4,5-b][1,4]dithiln-2-thione and 1,3-dithiolo[4,5-b] [1,4]dithiin2-one

By M. A. Beno", A. M. Kini" and J. M. Williams Chemistry and Materials Science Divisions, Argonne National Laboratory, Argonne, Illinios 60439, USA 
Table 4. Anisotropic thermal parmeters.

\section{$\mathrm{C}_{5} \mathrm{H}_{4} \mathrm{~S}_{4} \mathrm{O}$}

$\begin{array}{lllcccc}\text { Atom } & U_{11 \times 10^{4}} & U_{22 \times 10^{4}} & U_{33 \times 10^{4}} & U_{12 \times 10^{4}} & U_{13 \times 10^{4}} & U_{23 \times 10^{4}} \\ \text { S1 } & 433(3) & 340(3) & 634(4) & -69(2) & 97(3) & -1(3) \\ \text { S2 } & 385(3) & 319(3) & 611(4) & 45(2) & 19(2) & 3(3) \\ \text { S3 } & 337(3) & 466(4) & 1056(6) & 65(2) & 78(3) & 39(4) \\ \text { S4 } & 413(3) & 287(3) & 890(5) & -21(2) & 40(3) & -58(3) \\ \text { C1 } & 509(12) & 305(10) & 427(12) & 9(9) & 102(10) & 12(9) \\ \text { C2 } & 371(10) & 270(9) & 463(12) & 23(8) & 64(9) & -24(9) \\ \text { C3 } & 369(10) & 305(10) & 503(12) & 15(8) & 99(9) & 19(9) \\ \text { C4 } & 571(16) & 367(13) & 1200(26) & 48(11) & -31(16) & 67(15) \\ \text { C5 } & 586(15) & 449(14) & 1053(23) & 192(12) & 131(15) & -17(15) \\ \text { O1 } & 691(11) & 270(8) & 799(12) & 43(7) & 157(9) & 28(8)\end{array}$

\section{$\mathrm{C}_{5} \mathrm{H}_{4} \mathrm{~S}_{5}$}

$\begin{array}{llllllr}\text { Atom } & U_{11 \times 10^{4}} & U_{22 \times 10^{4}} & U_{33 \times 10^{4}} & U_{12 \times 10^{4}} & U_{13 \times 10^{4}} & U_{23 \times 10^{4}} \\ \text { S1 } & 494(4) & 402(4) & 351(3) & -104(3) & 108(3) & -28(3) \\ \text { S2 } & 464(4) & 419(4) & 458(4) & -113(3) & 88(3) & -136(3) \\ \text { S3 } & 645(5) & 434(4) & 401(4) & -142(4) & 119(3) & -125(3) \\ \text { S4 } & 615(5) & 485(4) & 663(5) & -151(4) & 349(4) & -95(4) \\ \text { S5 } & 609(5) & 652(5) & 386(4) & 65(4) & 141(3) & -117(4) \\ \text { C1 } & 361(13) & 383(13) & 319(12) & 49(11) & 9(10) & -19(11) \\ \text { C2 } & 354(13) & 389(14) & 341(12) & -10(11) & 89(10) & -34(11) \\ \text { C3 } & 331(12) & 351(12) & 271(11) & -4(10) & 22(9) & -9(10) \\ \text { C4 } & 471(17) & 610(19) & 565(18) & 68(15) & 181(14) & -92(16) \\ \text { C5 } & 659(20) & 581(19) & 377(14) & -13(17) & 130(14) & -68(14)\end{array}$

The complete temperature factor is $\exp \left[-2 \pi^{2}\left(a^{*} U_{11} h^{2}+b^{*} 2 U_{22} k^{2}+\left.c^{*} U_{33}\right|^{2}+2 a^{*} b^{*} U_{12} h k+2 a^{*} c^{*} U_{13} h l+2 b^{*} c^{*} U_{23} k l\right)\right]$. 
Table 5. Calculated hydrogen atom positional parameters.

$\begin{array}{llcl} & & \mathrm{C}_{5} \mathrm{H}_{4} \mathrm{~S}_{4} \mathrm{O} & \\ \text { Atom } & x & y & z \\ \mathrm{H} 4 \mathrm{~A} & 0.0058 & -0.2880 & 0.2506 \\ \mathrm{H} 4 \mathrm{~B} & 0.0637 & -0.2320 & 0.4350 \\ \mathrm{H} 5 \mathrm{~A} & 0.3306 & -0.2522 & 0.2674 \\ \mathrm{H} 5 \mathrm{~B} & 0.2029 & -0.2045 & 0.0928 \\ & & & \\ & & \mathrm{C}_{5} \mathrm{H}_{4} \mathrm{~S}_{5} & \\ & & & \\ \text { Atom } & x & y & z \\ \mathrm{H} 4 \mathrm{~A} & 0.5794 & 0.1241 & 0.6466 \\ \mathrm{H} 4 \mathrm{~B} & 0.6041 & 0.2402 & 0.5391 \\ \mathrm{H} 5 \mathrm{~A} & 0.7313 & 0.3963 & 0.6778 \\ \mathrm{H} 5 \mathrm{~B} & 0.8025 & 0.1512 & 0.6848\end{array}$



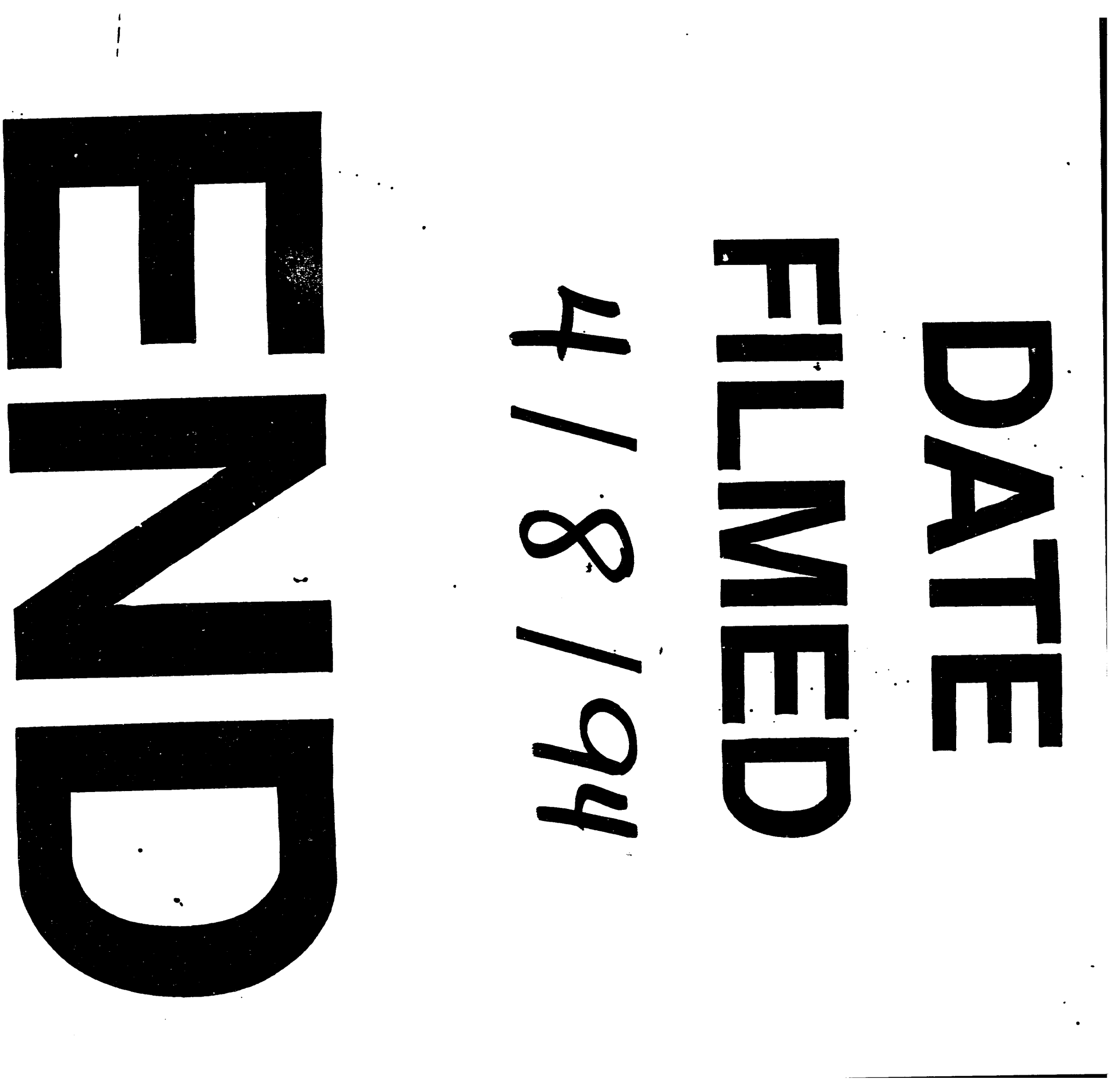
